\title{
Gerencialismo e dispersão de poder na relação Estado- educação: as traduções e os hibridismos do caso brasileiro
}

\author{
Management and dispersion of power in the State-education relationship: \\ translations and hybridisms of the brazilian case \\ Gerencialismo y dispersión de poder en la relación Estado-educación: las \\ traducciones y los hibridismos del caso brasileño
}

\section{IANA GOMES DE LIMA \\ LUÍS ARMANDO GANDIN}

\begin{abstract}
Resumo: Este texto tem como objetivo analisar a presença do gerencialismo no Estado brasileiro, examinando, em particular, uma de suas características centrais: a dispersão de poder. $\mathrm{Na}$ construção de nossa argumentação, nos utilizamos da contribuição de John Clarke e Janet Newman para o entendimento do gerencialismo e da dispersão de poder (1997; 2009), detalhando as premissas dessa concepção, que eles definem não apenas como uma forma de administração, mas como mudança cultural. $\mathrm{O}$ artigo mostra que a dispersão de poder se faz presente na relação entre Estado e educação no Brasil, mas examina também como uma das premissas de Clarke e Newman - a de que há sempre um processo de tradução e não mera transposição de concepções dominantes sobre como o Estado deve se organizar - está presente no caso brasileiro. Através da análise de casos concretos da política educacional brasileira, essa presença do gerencialismo "traduzido" é documentada.
\end{abstract}

Palavras-chave: dispersão de poder; gerencialismo; educação; Estado.

Abstract: This paper aims at analyzing the presence of managerialism in the Brazilian state, examining, in particular, one of its central characteristics: the dispersal of power. In building our argument, we resort to the contribution of John Clarke and Janet Newman to the understanding of managerialism and the dispersal of power $(1997 ; 2009)$, detailing the premises of this rationale, which they define not only as a form of administration but also as a cultural change. The paper shows that the dispersal of power is present in the relation between the state and education in Brazil, but also examines how one of Clarke and Newman premises - the one that always identify a process of translation and not a mere transposing of dominant rationales about how the state should be organized - is present in the Brazilian case. Through an analysis of concrete cases of Brazilian educational policy, this presence of a "translated" managerialism is documented.

Keywords: dispersal of power; managerialism; education; state.

Resumen: Este texto tiene como objetivo analizar la presencia del gerencialismo en el Estado brasileño, examinando, en particular, una de sus características centrales: la dispersión de poder. En la construcción de nuestra argumentación, utilizamos la contribución de John Clarke y Janet Newman para el entendimiento del gerencialismo y la dispersión de poder $(1997 ; 2009)$, detallando las premisas 
de esta concepción, que ellos definen no sólo como una forma de administración, sino como cambio cultural. El artículo muestra que la dispersión de poder se hace presente en la relación entre Estado y educación en Brasil, pero examina también como una de las premisas de Clarke y Newman - la de que hay siempre un proceso de traducción y no mera transposición de concepciones dominantes sobre cómo el Estado debe organizarse - está presente en el caso brasileño. A través del análisis de casos concretos de la política educativa brasileña, esa presencia del gerencialismo "traducido" es documentada.

Palabras clave: dispersión de poder; gerencialismo; educación; Estado.

\section{INTRODUÇÃO}

Estudar a relação entre o Estado e a educação é tarefa que exige uma complexa teoria que seja capaz de superar visões monolíticas do Estado. Uma parte significativa da literatura sobre essa relação reconhece os processos de recontextualização que ocorrem quando as políticas educacionais chegam às redes educacionais e às escolas, mas tende a homogeneizar o Estado e a vê-lo como uma instância dada, sem necessidade de explicação e com modelos fechados de intervenção. Assim, o movimento e as contradições tendem a ser capturados na implementação das ações do Estado, mas não no seu interior. Ao contrário, nesse artigo e em nossas pesquisas, nos filiamos à concepção de Gramsci: "a vida do Estado é concebida como um contínuo processo de formação e sucessivos equilíbrios instáveis" (GRAMSCI, 1971, p. 182). Com esse entendimento de que o Estado sempre precisa ser explicado e não funcionar apenas como uma explicação pronta (DALE, 2010) e de que ele sempre é fruto de acordos temporários -, buscamos, nesse artigo, examinar o gerencialismo, sua concepção de Estado e sua relação com a educação, tomando o exemplo brasileiro como campo de análise. Para isso, centramos na análise da manifestação de uma dinâmica do gerencialismo, que Clarke e Newman definem como dispersão de poder.

\section{O GERENCIALISMO E O ESTADO}

Clarke e Newman (1997) afirmam que o gerencialismo se apresenta como uma concepção que produz um Estado mais capaz de cumprir suas funções. Para que isso ocorresse, os autores apontam que três aspectos foram destacados como centrais: economia, eficiência e efetividade. Os três Es - assim denominados por esses autores - deveriam ser alcançados principalmente através da incorporação da lógica do mercado - entendida como superior à lógica do público - e de uma maior disciplina no serviço público para o oferecimento de serviços com melhor custo-benefício, o que seria garantido pela "liberdade para gerenciar". A premissa 
é que a grande solução para a chamada crise do Estado de Bem-Estar Social seria a introdução de soluções gerencialistas, da gerência como uma força de progresso, para que se chegue a formas de atuação mais próximas daquelas do mundo dos negócios.

Para Clarke e Newman o gerencialismo é mais do que uma forma particular de gerir o Estado. Para eles, o gerencialismo é uma concepção que busca uma transformação cultural e que, quando vivenciada no Estado, busca libertá-lo de suas amarras burocráticas, apontadas como parte de sua ineficiência, e criar a liberdade para que seus agentes gerenciem. Trata-se de dar aos gerentes dentro do Estado o poder e a "liberdade de tomar decisões sobre o uso de recursos institucionais para chegar aos resultados desejados" (1997, p. 56) ${ }^{1}$. Mas implica também criar organizações semiautônomas que se pensem como sendo empresas. Ao contrário de gerar uma autonomia crescente, o gerencialismo produz uma cadeia de monitoramento à distância dessas organizações. Como dizem os autores, o crescimento do que eles chamam de

\begin{abstract}
Nexo desempenho-avaliação era significativo para o funcionamento deste rol disperso de organizações contratadas para prestar serviços públicos: governá-las demandava novos tipos de agências de auditoria, inspeção, vigilância, fiscalização e avaliação de desempenho. Estas combinavam a procura de economia, eficiência e efetividade com a busca de valor por dinheiro no desenvolvimento de um equipamento para governar a distância (NEWMAN; CLARKE, 2012, p. 362).
\end{abstract}

Como podemos ver, não se trata apenas de um modelo de como gerenciar o Estado. Estamos de acordo com Clarke e Newman, que defendem que há um perigo em reduzir o gerencialismo à reestruturação organizacional do Estado, ainda que ele também tenha esse componente. Para aqueles autores, o gerencialismo busca mudar atitudes e não apenas práticas (CLARKE; NEWMAN, 1997). Para eles, o gerencialismo é uma concepção que busca uma mudança cultural que começa pela transformação do Estado, mas busca se estender à toda sociedade.

Defendemos que, embora ainda seja importante analisar os pressupostos e princípios da Nova Administração Pública, por exemplo, é fundamental entender e documentar a concepção que embasa esse modelo: o gerencialismo. Entendemos, assim como Clarke e Newman, que o gerencialismo, mais do que apenas um modelo de gestão do Estado, é "uma formação cultural e um distinto conjunto de ideologias e práticas que formam um dos fundamentos de um [...] 1 "Freedom to make decisions about the use of organisational resources to achieve desired outcomes"
(tradução nossa). 
acordo político" (Idem, 1997, p. ix)². Daí a necessidade de resistirmos a caracterizar a Nova Gestão Pública como "um modelo unificado de reforma aplicado 'de cima" (NEWMAN; Idem, 2009, p. 107)³. Estamos de acordo com essa premissa e por isso pensamos que entender o gerencialismo como essa nova "formação cultural” avança e complexifica em muito a discussão. Como dizem os autores,

A concepção de gerencialismo como um conjunto de discursos, práticas e tecnologias que pode ser combinado e recombinado com outras formas de poder oferece, cremos nós, uma melhor estrutura para entender a mudança como dinâmica e contestada (e não como um modelo que pode ser adotado ou abandonado) (Idem, Ibidem $)^{4}$

Modelos e suas combinações ganham e perdem espaços, mas formas de poder como o gerencialismo e outras que se combinam com ele precisam ser estudadas como aquelas que dão sustentação às mudanças mais amplas.

Além disso, trabalhar com a noção de movimento que nos propõem Newman e Clarke, nos permite destacar o papel os atores como "mediadores e tradutores da mudança" (NEWMAN; CLARKE, 2009, p. 20). Esse cuidado é ainda mais crucial no nosso caso, que buscamos analisar em que medida o gerencialismo influencia o Estado brasileiro em sua relação com a educação. Como dizem os autores,

Mesmo quando mudanças são experienciadas como impostas 'de cima', atores precisam encontrar formas de traduzi-las de modo que sejam mais ou menos congruentes com os contextos 'locais'. Tradução, portanto, nos afasta de noções de difusão de ideias, usualmente pressupostas como sendo vindas de fora a partir de uma fonte única da Nova Gestão Pública ou neoliberalismo anglo-saxões [...]. (Idem, ibidem). ${ }^{6}$

2 "a cultural formation and a distinctive set of ideologies and practices which form one of the underpinnings of an [...] political settlement” (tradução nossa).

3 “[...] as a unified template of reform applied "from above"” (tradução nossa).

4 The conception of managerialism as a set of discourses, practices and technologies that can be assembled and re-assembled with other forms of power offers, we think, a better framework for understanding change as dynamic and contested (rather than as a template that can be adopted or abandoned). (tradução nossa).

5 "[...] as mediators and translators of change". (tradução nossa).

$6 \quad$ "Even where changes are experienced as imposed 'from above', actors have to find ways of translating them that are more or less congruent with 'local' contexts. Translation, then, forms a valuable counter to notions of the diffusion of ideas, usually assumed to be outward from a single source of Anglo-American New Public Management or neo-liberalism [...]". (tradução nossa). 
Esse alerta, como dissemos acima, é crucial em nosso caso. Há sempre mediações e traduções e é preciso entender as particulares combinações existentes em cada contexto.

Uma última razão para focar no gerencialismo é que ele, ainda que ele, como forma de poder, não explique todas as mudanças no Estado nos últimos anos - isso não acontece nem na Inglaterra, onde Clarke e Newman identificamno com sua maior potência, muito menos no Brasil, com outras formas de poder em disputa, tais como o patrimonialismo, apenas para citar uma -, ele define o novo terreno onde a disputa se dá e, por isso, se apresenta como uma concepção que não pode ser ignorada.

Nesse artigo, não há espaço para abordar todas as características do gerencialismo e por isso optamos por centrar nossa atenção em uma dessas características que é a dispersão de poder. Destacamos que nem todas as características atribuídas por Clarke e Newman à dispersão estão presentes no caso brasileiro. No entanto, julgamos que há elementos suficientes para que a introdução de tal conceito nos permita identificar importantes características do gerencialismo no Estado brasileiro e sua relação com a educação.

\section{DISPERSÃO DE PODER: UMA CARACTERÍSTICA CENTRAL DO GERENCIALISMO}

A dispersão de poder é uma das características centrais do gerencialismo Segundo Clarke e Newman (1997, p. 29), “dispersão significou uma simultânea diminuição do Estado e o alargamento de seu alcance na sociedade civil. [...] Como estratégia de reconstrução do Estado, a dispersão [...] buscou disciplinar e transformar os tradicionais territórios institucionais de poder no Estado" Os autores explicitamente defendem o uso do conceito de dispersão e não de fragmentação. Eles afirmam que a noção de fragmentação enfatiza um movimento centrífugo, de esfacelamento do centro para as margens, sem indicar como os fragmentos são integrados. Clarke e Newman defendem que o conceito de dispersão captura muito melhor o processo que eles querem descrever. Dispersão implica um "cálculo estratégico" e não implica em uma desintegração. Ao contrário, usar o conceito de dispersão implica em prestar atenção aos "meios através dos quais o centro busca manter o comando ao mesmo tempo em que

\footnotetext{
$7 \quad$ "Dispersal has meant the simultaneous shrinking of the state and the enlargement of its reach into civil society $[\ldots]$. As a strategy of state reconstruction, dispersal [...] has sought to discipline and transform the old institutional sites of power in the state" (tradução nossa).
} 
distribui poder para a periferia" (CLARKE; NEWMAN, 1997, p. 25) ${ }^{8}$. Os autores afirmam que a dispersão de poder, que pode ser entendida em um primeiro momento, como a diminuição do papel do Estado, já que agentes não-estatais são responsabilizados pelo que antes era de responsabilidade única do Estado, deve ser vista, por outro ângulo, como a expansão do poder estatal: outras agências passam a ser uma extensão do Estado, que continua exercendo poder em diversas instâncias, através do envolvimento de novas formas de regulação financeira, contratação, monitoramento e vigilância.

A dispersão de poder conecta-se com o pressuposto gerencialista de que as instituições não-estatais proveriam os serviços de bem-estar com maior eficiência e qualidade do que o âmbito estatal. Tal pressuposto foi fortemente articulado pela Nova Direita - aqui entendida como a aliança entre neoliberais e neoconservadores - na Inglaterra que, quando da crise dos anos de 1970, realizou duras críticas ao Estado de Bem-estar social, principalmente ao afirmar que o Estado gastava muito com as políticas sociais e provia serviços de má qualidade. Para a Nova Direita, era necessário que a agenda de negócios passasse a ser articulada em nome do mercado, do cliente, da nação e do espírito empresarial. A gestão burocrática foi definida, especialmente pelos grupos neoliberais e neoconservadores, como uma forma de organização inapropriada e ineficiente de administrar o Estado, que não se adaptava às demandas complexas do mundo moderno. As qualidades do gerencialismo foram, assim, construídas a partir dos problemas do antigo modelo administrativo, criando-se um binarismo entre gerencialismo e burocracia - uma das marcantes características do Estado de Bem-estar social (OFFE, 1990) - havendo um rebaixamento do velho e a idealização do novo (CLARKE; NEWMAN, 1997). Esse binarismo provê um ponto de partida para pensar a reconstrução do poder associada a processos de gerenciamento. Algumas das oposições criadas foram: setor privado x setor público, gestão x administração pública, valores de mercado x valores de serviço público, consumidores x cidadãos.

Clarke e Newman reconhecem, no entanto, que essa definição de um binário entre burocracia e gerencialismo é muito mais um exercício discursivo do que algo que de fato se materializa como a existência única de um ou outro desses polos. Isso quer dizer que práticas burocráticas podem conviver com ações gerencialistas no âmbito do Estado. Esse entendimento nos parece crucial, pois ele permite entender os modelos híbridos e as contradições que identificaremos no caso brasileiro. Outro aspecto importante que os autores enfatizam é que a

8 "means by which the centre attempts to maintain command while distributing power to periphery" (tradução nossa). 
“dispersão torna o exercício do poder e da tomada de decisão gerencializadas instáveis” (CLARKE; NEWMAN, 1997, p. 31)9 , o que também abre espaços para a contradição e hibridismos.

$\mathrm{Na}$ próxima seção, tratamos de examinar exemplos de ações do Estado brasileiro que mostram um campo redefinido pela influência do gerencialismo, mas ao mesmo tempo um Estado que está permeado por hibridismos e contradições.

\section{O GERENCIALISMO E A DISPERSÃO DE PODER NO CASO BRASILEIRO}

O gerencialismo foi bastante difundido no Brasil nos anos de 1990, principalmente, através do ex-ministro Luiz Carlos Bresser Pereira e sua equipe, que atuou frente ao Ministério de Administração e Reforma do Estado (Mare), de 1995 a 1998, propondo mudanças na prática de gestão estatal. A concepção gerencialista e suas implicações para o Estado também foram difundidas pelo exministro da educação Paulo Renato Souza (que atuou como ministro de 1995 a 2002) e sua equipe, que apontava, assim como Bresser Pereira, a necessidade de reformar o Estado - trazendo um enfoque para o âmbito educacional -, como forma de tornar a educação mais eficiente.

Peroni (2003) destaca que, no Brasil, nos anos de 1990, grupos direitistas criticavam a administração estatal, acusando os serviços estatais de serem ineficientes e de má qualidade). O diagnóstico realizado pelo ex-ministro Bresser Pereira foi que a origem da crise era o próprio Estado, sendo este ineficiente em suas políticas e em sua forma administrativa (Idem), sendo acusado de gastar mais do que arrecadava (LIMA, 2009). A partir deste diagnóstico e tendo como base os pressupostos gerenciais, o Mare elaborou um documento intitulado "Plano Diretor da Reforma do Aparelho do Estado" (BRASIL, 1995), que demonstrava a intenção de tornar o Estado brasileiro mais regulador e administrador do que provedor de serviços e bens, controlando os resultados dos serviços ao invés de seu processo, definindo objetivos, propiciando autonomia ao administrador e estimulando a competição dentro do próprio Estado. Uma das formas de estimular a competição e de melhorar a qualidade dos serviços, proposta pelo Plano Diretor de Reforma do Aparelho do Estado (BRASIL, 1995), foi o repasse, para agentes não-estatais, da responsabilidade do provimento de serviços. Estratégias como a privatização (venda de empresas públicas para instituições privadas), publicização (transferência para setores públicos não-estatais - ONGs, sociedade civil - de

9

"Dispersal makes the exercise of managerialised power and decision-making unstable" (tradução nossa). 
serviços sociais e científicos) e a terceirização (transferência de serviços auxiliares e de apoio para o setor privado) passaram a se fazer presentes (PERONI, 2003). Tal ação pode ser entendida como a dispersão de poder analisada por Clarke e Newman (1997) no contexto inglês. Nogueira (2011) afirma que o "paradigma gerencial" foi fundamental para as reformas realizadas no Brasil a partir dos anos de 1990, quando grupos direitistas passaram a apontar o quanto o padrão burocrático representava um entrave frente às mudanças promovidas pela globalização. O objetivo era mostrar que a eficácia estatal estava profundamente relacionada à introdução de mecanismos de mercado na gestão pública.

Conforme demonstrado acima, estudos e documentos (PERONI, 2003; LIMA, 2009; NOGUEIRA, 2011; BRASIL, 1995) apontam características gerencialistas - dentre elas, a dispersão de poder - que passaram a fazer-se presentes no contexto do Estado brasileiro. No entanto, embora haja muita produção sobre a introdução do gerencialismo no Brasil nos anos 1990, há muito menos estudos sobre essa influência nos anos de "governos democrático-populares" (OLIVEIRA, 2015). Passamos, a partir de agora, a examinar exemplos, no período desses governos, da presença de influências da concepção gerencialista e onde se pode capturar a presença de hibridismos e contradições. Lembramos que Clarke e Newman, como mostramos desde o início desse artigo, já alertavam para que buscássemos, em nosso trabalho de pesquisadores, essas contradições que constituem a tradução do gerencialismo no âmbito dos Estados nacionais.

Para exemplificar a discussão que estamos fazendo, entendemos que o Índice de Desenvolvimento da Educação Básica (Ideb), instituído em 2007 e incorporado como um aspecto importante no Plano de Desenvolvimento da Educação (BRASIL, 2008) serve como um interessante caso de uma prática influenciada pelo gerencialismo no âmbito educacional. No entanto, como vimos discutindo nesse artigo, seria uma simplificação afirmar que há uma mera transposição dessa concepção no Brasil. A introdução desse índice não pode ser entendida como sendo apenas resultado de uma concepção gerencialista, uma vez que políticas elaboradas a partir do Ideb não trouxeram apenas esta lógica, mostrando, assim, a complexidade do cenário brasileiro.

O Ideb tem servido como um guia para as ações do Estado na educação, pois tem sido usado como referência para a realização de várias ações como o Plano de Ações Articuladas (PAR), o Programa Dinheiro Direto na Escola (PDDE), o Plano de Desenvolvimento da Escola (PDE Escola) e o Mais Educação, por exemplo. É importante ressaltar que para a criação do Ideb foi necessária a criação da Prova Brasil - que ocorreu no ano de 2005, ainda no primeiro mandato do presidente Luiz Inácio Lula da Silva -, caso contrário, não seria possível estabelecer uma nota por escola, o que, segundo o documento do Plano de Desenvolvimento 
da Educação (PDE), possibilitou, assim, “orientar o apoio financeiro da União (transferências voluntárias) e o apoio técnico do Ministério da Educação aos sistemas educacionais (gestão educacional)" (BRASIL, 2008, p. 15). Este índice passa a indicar, através das avaliações associadas ao fluxo, quais são as instituições com boas práticas e aquelas que apresentam insuficiências. Através do que será apresentado ao longo deste subitem, constatamos que o Ideb é um exemplo da imbricação entre as avaliações de larga escala e as características do gerencialismo, pois: 1. Promete transparência - a ideia é que a nota do Ideb tornaria clara quais são as boas e as más escolas; 2. Apresenta, para os pais - que seriam, neste caso, os clientes - a "qualidade" de um serviço público de forma individualizada (por escola); e 3. Estabelece uma meta (a melhoria na nota do Ideb) a ser seguida pelas instituições escolares, o que traria eficiência.

O Índice de Desenvolvimento da Educação Básica pode ser lido à luz das teorias de Ball (2010) e Maguire (2013), que apontam que, a partir do pressuposto da avaliação como instrumento de medição, a qualidade tem sido reduzida à obtenção de bons resultados nos testes, mostrando, assim, o quanto a educação tem se referido aquilo que pode ser mensurável (MAGUIRE, 2013). Ademais, o Ideb traz, em si, outro pressuposto gerencialista, que é a ideia de deixar claro para os clientes o nível do serviço público oferecido: através do Ideb, a ideia é que as famílias possam saber a qualidade do ensino que está sendo ofertado na escola em que estudam os seus filhos.

Além de ser o principal índice que tem balizado o que é qualidade na educação brasileira, o Ideb também passou a servir de padrão para programas de gestão e financiamento da educação, como é o caso do Programa Dinheiro Direto na Escola (PDDE), do Plano de Desenvolvimento da Escola (PDE Escola) e do Plano de Ações Articuladas (PAR), geridos pelo Fundo Nacional de Desenvolvimento da Educação (FNDE) - uma autarquia do MEC. Isto significa o estabelecimento de uma vinculação entre as notas das escolas no Ideb ao financiamento e à gestão. No entanto, diferentemente de políticas de caráter gerencialista no contexto inglês e outros, por exemplo, em que escolas com menores notas nos testes eram punidas ou, muitas vezes, fechadas (AFONSO, 2009; FREITAS, 2012; GUISBOND; NEILL; SCHAEFFER, 2012), as escolas que passaram a ser auxiliadas, a partir do Ideb, foram as que tinham os índices mais baixos e não os mais altos (BRASIL, 2008).

O repasse de verbas para as escolas com menor Ideb, segundo o site do $\mathrm{FNDE}^{10}$, é feito através do PDE Escola (que está compreendido dentro 
do PDDE). De acordo com as informações do site do FNDE"1: "Os recursos são repassados para as unidades de ensino das redes estaduais e municipais que aderiram ao Plano de Metas Compromisso Todos pela Educação e planejaram a implementação do Plano de Desenvolvimento da Escola (PDE Escola)". O repasse de recursos depende do número de alunos por escola, podendo ser de 15 mil reais (escolas com até 99 alunos) até 75 mil reais (mais de 3.999 estudantes) ${ }^{12}$.

É importante ressaltar, no entanto, que inicialmente, quando do estabelecimento do Ideb e do lançamento do Plano de Desenvolvimento da Educação, a vinculação entre financiamento e o Ideb também trazia a ideia de premiar as escolas que cumprissem as metas. Isto fica claro no discurso do então Ministro da Educação, Fernando Haddad, no lançamento do Plano de Desenvolvimento da Educação, quando afirmou que:

Nós queremos, nos valendo do Programa Dinheiro Direto na Escola (PDDE), premiar as escolas que cumprirem as suas respectivas metas. De maneira que a escola, se tem um indicador de zero a dez em um ponto e a sua meta de um e meio para o ano de 2007, essa escola vai receber um adicional, não é punição, um adicional no seu PDDE, a partir de 2008, de 50\% do valor. (HADDAD, 2007).

No discurso de Haddad no lançamento do PDE, é possível visualizar que a intenção era premiar as escolas que atingissem a meta. Estes aspectos referentes à premiação e punição estão contemplados no documento do Plano de Desenvolvimento da Educação, no qual é afirmado que:

Outro equívoco comum é a defesa de um sistema de incentivos composto de prêmios e punições, em geral de caráter pecuniário, às escolas ou às redes educacionais que cumprirem ou não metas de qualidade, em geral preestabelecidas. Esta perspectiva desconsidera o fato de que restringir o financiamento de escolas ou sistemas educacionais por queda de desempenho pode significar punir uma segunda vez aquele que já não viu respeitado seu direito de aprender - o educando. (BRASIL, 2008, p. 22).

Este é um ponto que merece atenção por mostrar algumas das particularidades do Estado brasileiro e aquilo que Newman e Clarke (2009) apontam como múltiplas formas de poder coexistentes. Ao tomar a centralidade da avaliação, a criação de um índice que tem como objetivo a responsabilização das escolas e das comunidades, poderia se esperar que o próximo passo, dentro de uma lógica neoliberal e/ou gerencialista, seria a punição das escolas com menores

\footnotetext{
11 http://www.fnde.gov.br/ - Acesso em: 14 de abril de 2014.

12 Dados referentes ao ano de 2007 disponíveis no site do Fundo Nacional de Desenvolvimento da Educação.
} 
notas, detectadas, assim, como as menos eficientes e qualificadas na prestação de serviço. No entanto, é justamente o contrário que ocorre e isso, no PDE, pode ser lido dentro de uma perspectiva de justiça social (YOUNG, 2006) e da busca por maior igualdade no sistema de educação, quando é afirmado no documento - como mostrado no trecho acima - que a punição poderia significar prejudicar uma segunda vez quem já não viu respeitado o seu direito de aprender e quando está escrito que: "A razão de ser do PDE está precisamente na necessidade de enfrentar estruturalmente a desigualdade de oportunidades educacionais" (BRASIL, 2008, p. 5).

A política de repasse de verba para as escolas com piores notas no Ideb demonstra uma articulação (HALL, 2009), no que se refere às ações do Estado na educação básica, entre diferentes aspectos: ao mesmo em que há uma ênfase na mensuração da qualidade através do Ideb e na busca de eficiência - aspectos relacionados aos pressupostos gerenciais -, há, também, um apoio às escolas que têm menores notas, o que, segundo o próprio documento do PDE (BRASIL, 2008), ocorre para não prejudicar uma segunda vez quem já não viu respeitado o seu direito de aprender e para enfrentar estruturalmente a desigualdade de oportunidades educacionais. Através do repasse de verbas para as escolas com menor Ideb, pode-se perceber que essas ações podem ser entendidas como muito mais próximas de uma concepção de Bem-Estar social, do que gerencialista; o que temos aqui é o Estado provendo melhorias nas condições das escolas que mais necessitam de sua ação. Assim, não há uma total descentralização das responsabilidades para as escolas, uma vez que o Estado ainda chama para si, através de uma política de caráter redistributivo, a responsabilidade de auxiliar as instituições escolares. Ainda assim, essa ação ainda tem marcas gerencialistas, já que o repasse de verbas para as instituições escolares inclui um caráter descentralizador, pois as escolas precisam gerir os seus recursos e melhorar sua gestão em busca de maior eficiência e, logo, melhores notas no Ideb. Ademais, a ideia de qualidade na educação continua vinculada ao entendimento da educação como algo mensurável.

Estas políticas contraditórias podem ser explicadas à luz dos processos de proliferação de políticas e do surgimento de vazios de políticas, elementos trazidos por Clarke e Newman (1997) ao realizarem uma análise do contexto inglês quando das transformações ocorridas no Estado após a crise de 1970. Segundo os autores, esses processos ocorrem devido à complexa relação entre controle centralizado e dispersão de poder. Os autores apontam que, em uma visão gerencialista do Estado, a política e os processos políticos são vistos como negativos, portanto, busca-se despolitizar as políticas. No entanto, destacam que vários processos políticos são difíceis de serem despolitizados, o que gera que um 
governo busque uma grande gama de intervenções políticas para uma garantia de controle. Dada esta dificuldade de despolitização, se faz necessário um conjunto ainda maior de intervenções políticas para assegurar ao público que está tudo sobre controle. Tal proliferação é um indicador do esforço por legitimidade de um governo. O alerta dos autores é que, na medida em que há tal proliferação, surgem inúmeras contradições e falta de coerências entre essas políticas. E é aí que ocorre o surgimento de vazios de políticas, que representam esta falta de coerência e esta fragmentação, como se não houvesse um rumo a ser seguindo pelas políticas. Esta falta de direção, este vazio, também é fruto das pressões existentes em relação à política, que precisa atender a diferentes objetivos tendo em vista os variados atores envolvidos no processo de governança educacional. Esse entendimento representa uma boa lente de análise para o caso brasileiro que, apesar de suas particularidades, também busca atender a diferentes grupos, o que gera políticas bastante contraditórias.

A proliferação de instituições não-estatais que têm atuado no e como Estado (DALE, 2010) no Brasil também traz em si características gerenciais. Conforme apontam Altmann (2002) e Lima (2009), na década de 1990, houve, através de documentos oficiais brasileiros (Constituição de 1988 e LDB de 1996), um incentivo ao estabelecimento de parcerias entre entidades públicas e privadas. No entanto, este incentivo não se limita a esta década, o que pode ser exemplificado através do Fundo de Manutenção e Desenvolvimento da Educação Básica e de Valorização dos Profissionais da Educação (FUNDEB), aprovado em 2007. Esta foi outra iniciativa na qual se pode verificar a porosidade entre as fronteiras do público e privado, abrindo a possibilidade do uso de recursos públicos para instituições escolares sem fins lucrativos, pois, conforme a Lei n. 11.494/2007, a distribuição de recursos do Fundeb pode ser realizada para as instituições comunitárias, confessionais ou filantrópicas sem fins lucrativos e conveniadas com o poder público (BRASIL, 2007). Esta perspectiva teve prosseguimento no II Plano Nacional de Educação, aprovado em 2014, quando, na meta 20, os $10 \%$ do PIB para a educação não constituem apenas recursos para a educação pública, podendo, assim, serem destinados para instituições públicas não-estatais (BRASIL, 2014). O II PNE é um bom exemplo do quanto as organizações nãoestatais têm tido força para colocar em pauta suas reivindicações.

Através destes documentos, o que se pode perceber é que houve uma continuidade, desde os anos de 1990, de um movimento, por parte do Estado brasileiro, que favorece o fortalecimento destas organizações: na medida em que o Estado legitima a participação destas instituições como parceiras no provimento de políticas educacionais, há uma motivação para que tais organizações se tornem mais fortes em termos técnicos e políticos. A legitimação destas fundações 
como parceiras do Estado, por sua vez, está alicerçada na premissa gerencialista de que a gestão privada é mais eficiente que a gestão pública. Assim, o repasse para instituições não-estatais do que antes era de responsabilidade do Estado implica no entendimento que o serviço antes provido pelo âmbito estatal terá melhor relação custo-benefício. Além disso, gera a noção de que essas agências estabelecem o parâmetro de uma ação eficiente e de resultados, o que tenderia a balizar o parâmetro de avaliação das ações do próprio Estado. Esta foi uma das ideias difundidas pela Nova Direita, quando da crise dos anos de 1970 na Inglaterra, qual seja, de que o âmbito privado é mais confiável, por sua expertise e eficiência, do que o público e, por isso, o Estado deveria aproximar-se, em sua gestão, da lógica do mercado. Isto ajudou a criar um binarismo da gestão versus administração pública, que foi bastante difundida no Brasil desde os anos de 1990, sendo a gestão privada associada à eficiência, eficácia e efetividade e a administração pública a uma forma de organização inapropriada e ineficiente (NOGUEIRA, 2011).

Para exemplificar a continuidade do estabelecimento de parcerias entre o Estado e instituições não-estatais, no âmbito da União, é a Olimpíada da Língua Portuguesa - Escrevendo o Futuro, um concurso de produção de textos para alunos de escolas públicas de todo o país, do $5^{\circ}$ ano do ensino fundamental ao $3^{\circ}$ ano do ensino médio. A ideia é que os professores desenvolvam uma sequência didática para aplicar nos alunos e que a turma realiza escritas e reescritas de uma redação. No site ${ }^{13}$, é informado que, para além da seleção e premiação de textos, a Olimpíada propõe para o professor de língua portuguesa uma formação que o auxilie na reflexão e compreensão da função social da escrita, fortalecendo o seu trabalho em sala de aula. Ao total, são cinco etapas que compõem o programa, sendo estas referentes ao âmbito escolar, municipal, estadual, regional e, por fim, nacional.

Este programa - que quando desenvolvido pelo Itaú Social, chamava-se apenas "Escrevendo o Futuro" - tinha uma escala pequena de abrangência. Em 2008, o Ministério convidou a Fundação Itaú Social para uma conversa com o objetivo de conhecer melhor o programa. Naquele momento, então, foi decidido que o MEC entraria como parceiro. Assim, o programa se tornou a "Olimpíada da Língua Portuguesa - Escrevendo o Futuro”, um programa do Ministério da Educação. A partir desse ano, o Ministério compartilhou as estratégias de mobilização do programa, junto a professores, secretarias, distribuindo os materiais. Toda a metodologia de formação da Fundação Itaú Social foi disponibilizada em um portal de formação do professor. Com a parceria do MEC, houve uma 
capilarização do programa, que ganhou uma escala muito maior, contando, a partir de então, com a participação de entre 5.100 e 5.200 municípios. De acordo com Lima (2016), a ideia da parceria surgiu porque o ex-ministro Fernando Haddad encantou-se pelo desenho do programa, afirmando que, no MEC, não havia tempo de desenvolver uma tecnologia como aquela. A autora ainda destaca que Pilar Lacerda, ex-secretária da SEB, concorda que, para fazer uma iniciativa parecida com esta, seria necessário vencer as barreiras burocráticas do Estado. A realização desta parceria pelo Ministério representou ter, para Pilar Lacerda, um ganho tanto para o MEC quanto para a Fundação Itaú Social, que passou a ter imensa visibilidade. Cabe destacar que o uso de programas desenvolvidos por instituições não estatais pode ser entendido por aquilo que Clarke e Newman (1997) definem como uma porosidade das fronteiras entre público e privado ou pelo que Bresser Pereira denomina publicização (BRASIL, 1995), ou seja, a transferência, para setores públicos não-estatais, de serviços sociais e científicos. Isso é diferente de ações denominadas terceirização (PERONI, 2003) ou da transferência de responsabilidade para o domínio do setor informal (CLARKE; NEWMAN, 1997), que ocorreu de forma mais contundente nas ações do Estado brasileiro em relação à educação nos anos de 1990 (PERONI, 2003).

Ainda em relação às ações do Estado brasileiro na educação no período de 2002 a 2014, atores não estatais demonstram-se incomodados com aquilo que denominam "Estado bem pesado" (LIMA, 2016). De acordo com esse autor, representantes de organizações não estatais que têm sido importantes na formulação de políticas educacionais no cenário brasileiro apontam que, durante os anos de 1990, percebem que o âmbito estatal se aproximava mais de uma concepção gerencialista, afirmando que, depois do ano de 2002, o Estado passou a ter representações em muitos setores, fazendo-se presente, voltando, assim, a ter a postura de "Estado forte". No entanto, a representação em muitos setores é uma das características do próprio gerencialismo - conforme destacam Clarke e Newman (1997) - que pode ser entendida como uma das contradições do Estado gerencialista: ao mesmo tempo em que a dispersão de poder pode ser entendida como diminuição do papel do Estado pode ser vista, por outro lado, como expansão do poder estatal, que, também através das agências nãoestatais, começa a exercer outros papéis como regulação financeira, contratação, monitoramento e vigilância Contudo, cabe destacar que a crítica destes atores não estatais a um "Estado forte" parece aproximar se muito mais do fato de ser o âmbito estatal ainda entendido como muito burocrático do que, efetivamente, por ter muitas representações (LIMA, 2016). Assim, na visão destes atores, o fato de o Estado ter voltado a ser forte nos últimos anos acaba trazendo alguns problemas para a modernização estatal, exemplificados pela pouca flexibilidade 
e pela pouca agilidade. Este "Estado forte" pode ser entendido, por exemplo, a partir de ações e políticas que poderiam ser entendidas como assistencialistas, ou seja, destinadas à população excluída e que estiveram presentes no período de 2003 a 2013, conforme a análise de Gentili e Oliveira (2013).

Esses autores afirmam que houve avanços na política educacional nesse período, principalmente no que se refere às ações destinadas à população tradicionalmente excluída do processo educacional, buscando-se, assim, maior igualdade, que havia sido negada ao povo brasileiro. Eles destacam que "nesses pouco mais de dez anos, importantes iniciativas foram tomadas para ampliar e assegurar o direito à educação, especialmente no que se refere à universalização da educação básica e sua melhoria e à democratização do acesso à educação" (p. 254). Destacam ainda que a educação, neste período, contribuiu para a "promoção de uma política social mais justa [o que] foi relevante. A taxa de miséria caiu $8 \%$ em 2004 com relação a 2003, primeiro ano do mandato do presidente Lula. No mesmo ano, mais de 8 milhões de pessoas saíram da pobreza" (Idem, p. 259). Esses avanços não podem ser lidos à parte da ênfase dada às avaliações de larga escala e à inserção do gerencialismo na gestão educacional. O que queremos destacar, neste momento, é que não há como negar o avanço educacional ocorrido no período de 1995 a 2014, muito menos o quanto as políticas educacionais, desde o primeiro mandato do ex-presidente Luiz Inácio Lula da Silva, estiveram preocupadas com aqueles que tradicionalmente foram marginalizados do processo educacional. No entanto, algumas das próprias políticas dedicadas a essa parcela da população também possuem características gerencialistas, como é o caso do Programa Universidade para Todos (Prouni). Esse programa é trazido por Gentili e Oliveira (2013) como ação incisiva de ampliação do acesso à educação superior "direcionada a um público específico, os egressos do ensino médio em situação de pobreza” (p. 256). Ainda em relação a esse programa, os autores afirmam que:

A expressiva expansão das oportunidades de acesso ao ensino superior para a população mais pobre foi, em boa medida, garantida mediante um aproveitamento socialmente mais justo das vagas disponíveis nas universidades privadas cuja ampliação foi produto das políticas de mercantilização educacional promovidas durante o governo de Fernando Henrique Cardoso. (Idem, ibidem).

Ainda neste mesmo texto, os autores apontam que, em suma, o Prouni contribuiu para a democratização e o acesso e "não fez outra coisa senão dotar de sentido público e social um segmento do sistema educacional marcado por prebendarismo, especulação, baixa qualidade, interesse de lucro e falta de controle estatal" (Idem, Ibidem). Contudo, em outro texto escrito apenas por Oliveira (2015), a autora afirma que o Prouni é um exemplo de programa que demonstra as 
contraditoriedades presentes nos mandatos de Luiz Inácio Lula da Silva e Dilma Rousseff, pois "ao mesmo tempo que permitem acesso aos mais necessitados, respondem a demandas dos setores privados empresariais" (OLIVEIRA, 2015, p. 636). Portanto, o que se pode perceber em relação a esse programa é que ele é permeado por contradições e articulações, o que afirmo existir, também, em relação a outros programas e às próprias ações do Estado na Educação Básica.

As características não gerencialistas destacadas acima são importantes para demonstrar que houve mudanças nas ações do Estado na Educação Básica entre os governos que abarcam o período de 1995 a 2014. No entanto, nosso objetivo, aqui, não é tratar especificamente dos governos, mas entender as ações do Estado, tendo a compreensão, assim como Hay, Lister e Marsh (2006) e Dale (1988), de que governo e Estado se diferenciam, sendo que os governos vêm e vão, enquanto o Estado permanece como um conjunto institucional, que se mantém ao longo do tempo (HAY; LISTER; MARSH, 2006). Dale (1988) aponta que o governo é uma parte importante e a mais visível do Estado, mas não é sua totalidade. $\mathrm{O}$ autor afirma que isso pode ser demonstrado pelo fato de que o Estado continua funcionando mesmo na ausência de governos. O governo tem limites dentro de um Estado. Portanto, mesmo que haja diferenças entre os governos, sustentamos que as avaliações de larga escala e a concepção gerencialista continuaram sendo importantes nas ações do Estado na Educação Básica no período de 1995 a 2014.

Assim, apesar de todas estas particularidades do Estado brasileiro, que ainda é forte e bastante centralizado, tem características patrimonialistas, coronelistas e populistas (FAORO, 2001) e no qual há a existência concomitante de aspectos gerenciais e não-gerenciais, as avaliações de larga escala e os pressupostos gerenciais têm sido importantes como orientadores das ações do Estado na Educação Básica.

\section{CONSIDERAÇÕES FINAIS}

O que foi trabalhado ao longo deste texto aponta que, no período de 1995 a 2014, há uma continuidade em relação à prática da dispersão de poder com gradativo aumento do número de instituições não-estatais que se fazem presentes na relação Estado e educação. Identificamos uma proliferação de atores não estatais no cenário educacional brasileiro e de uma porosidade das fronteiras entre público e privado. Um dos exemplos apresentados mostra o Fundeb como ação que favoreceu a proliferação desses atores, abrindo a possibilidade do uso de recursos públicos para instituições não-estatais e permitindo que tais instituições realizassem funções antes unicamente do Estado. 
É importante destacar que a dispersão de poder não implica somente no repasse de responsabilidades para atores não-estatais, mas, ao favorecer a proliferação desses atores propicia, também, um empoderamento desses agentes como interlocutores do Estado, que passam a ter maior legitimidade nas disputas de poder que permeiam o âmbito estatal. Nesse sentido, foi importante mostrar a existência de uma aproximação entre os agentes não estatais e o Estado, que passam a oferecer serviços e programas, como é o caso da Olimpíada da Língua Portuguesa - Escrevendo o Futuro, antes unicamente de responsabilidade estatal.

Defendemos que a legitimação dessas parcerias entre instituições não estatais e o Estado tem como uma das premissas que a eficiência e a efetividade devem ser alcançadas pelo Estado - administração pública - através da incorporação da lógica que embasa a administração privada (gestão), entendida, pelos defensores do gerencialismo, como superior à administração estatal (CLARKE; NEWMAN, 1997). Os exemplos trazidos neste artigo mostram que muitas parcerias entre o Estado e as instituições não estatais são vistas como salutares, tendo em vista a capacidade que essas instituições têm de inovar, quando comparadas ao Estado.

Por fim, cabe destacar que, na medida em que há dispersão de poder e são inseridas, através de agentes não estatais, premissas gerencialistas no Estado, há a produção de novos discursos sobre o público: accountability público, governança pública, participação pública, valor público e muitos outros (NEWMAN; CLARKE, 2009). Segundo esses autores, todos esses discursos produzem novos argumentos sobre o papel dos serviços públicos mesmo quando estes não fazem mais parte de um setor público. Isto está relacionado à dispersão que ocorre em relação aos serviços públicos, que, através de uma multiplicidade de "núcleos de negócios", geram um efeito contraditório: simultaneamente multiplicam o número de organizações, grupos e agências que advogam "falar pelo público", e, ao mesmo tempo, desintegram o Estado, o que significa que nenhuma dessas organizações representa o interesse público como um todo. Cada organização persegue seus interesses no negócio, mais ou menos de forma isolada, fazendo, assim, com que concepções mais amplas de esfera pública ou de bem público tendam a ser ofuscadas. Isso não quer dizer que o gerencialismo tenha tomado todas as práticas do Estado brasileiro - como insistimos, há um processo de tradução, que implica em contradição e hibridismo - mas mostra que o campo no qual as decisões sobre as políticas educacionais ocorrem está encharcado pelo gerencialismo e sua proposta de mudança cultural. Mais estudos são necessários para analisar as consequências desse processo. 


\section{REFERÊNCIAS}

AFONSO, Almerindo Janela. Nem tudo o que conta em educação é mensurável ou comparável. Crítica à accountability baseada em testes estandardizados e rankings escolares. Revista Lusófona de Educação, Lisboa, n. 13, p. 13-29, 2009.

ALTMANN, Helena. Influências do Banco Mundial no projeto educacional brasileiro. Educação e Pesquisa, São Paulo, v. 28, n. 1, p. 77-89, jan./jun. 2002.

BALL, Stephen J. Performatividades e Fabricações na Economia Educacional: rumo a uma sociedade performativa. Educação e Realidade, Porto Alegre, v. 35, n. 2, p. 37-56, mai./ago. 2010.

BRASIL, Lei n. 11.494, de 20 de junho de 2007. Regulamenta o Fundo de Manutenção e Desenvolvimento da Educação Básica e de Valorização dos Profissionais da Educação - FUNDEB, de que trata o art. 60 do Ato das Disposições Constitucionais Transitórias; altera a Lei no 10.195 , de 14 de fevereiro de 2001; revoga dispositivos das Leis nos 9.424, de 24 de dezembro de 1996, 10.880, de 9 de junho de 2004, e 10.845, de 5 de março de 2004; e dá outras providências.

BRASIL. Plano Nacional de Educação 2014-2024: Lei no 13.005, de 25 de junho de 2014, que aprova o Plano Nacional de Educação (PNE) e dá outras providências. Brasília: Câmara dos Deputados, Edições Câmara, 2014.

BRASIL. Ministério da Educação. O Plano de Desenvolvimento da Educação: razões, princípios e programas. Brasília: Instituto Nacional de Estudos e Pesquisas Educacionais Anísio Teixeira, 2008.

BRASIL. Ministério da Administração e Reforma do Estado. Plano Diretor da Reforma do Aparelho do Estado. Brasília, 1995.

CLARKE, John; NEWMAN, Janet. The Managerial State: power, politics and ideology in the remaking of Social Welfare. London: Sage Publications, 1997.

DALE, R. A sociologia da educação e o estado após a globalização. Educação e Sociedade, Campinas, v. 31, n. 113, p. 1099-1120, out./dez. 2010. 
DALE, Roger. A Educação e o Estado capitalista: contribuições e contradições. Educação e Realidade, Porto Alegre, v. 13, n. 1, p. 17-37, jan./jul. 1988.

FAORO, Raymundo. Os donos do poder: formação do patronato político brasileiro. $3^{\text {a }}$ ed. rev. São Paulo: Globo, 2001.

FREITAS, Luiz Carlos. Os reformadores empresariais da educação: da desmoralização do magistério à destruição do sistema público de educação. Educação e Sociedade, Campinas, v. 33, n. 119, p. 379-404, abr/jun. 2012.

GENTILI, Pablo; OLIVEIRA, Dalila Andrade. A procura da igualdade: dez anos de política educacional no Brasil. In: SADER, Emir (org.). 10 anos de governos pós-neoliberais no Brasil: Lula e Dilma. São Paulo: Boitempo; Rio de Janeiro: FLACSO, 2013. p. 253-262.

GRAMSCI, Antonio. Selections from the Prison Notebooks. New York: International Publishers, 1971.

GUISBOND, Lisa; NEILL, Monty; SCHAEFFER, Bob. A década de progresso educativo perdida sob a NCLB: que lições tirar desse fracasso político? Educação e Sociedade, Campinas, v. 33, n. 119, p. 405-430, abr/jun. 2012.

HADDAD, Fernando. Ministério da Educação. Discurso do ministro Fernando Haddad no lançamento do PDE. 24 de abril de 2007.

HALL, Stuart. Da diáspora: identidades e mediações culturais. Belo Horizonte: Editora UFMG, 2009.

HAY, Colin; LISTER, Michael. Introduction: theories of the State. In: HAY, Colin; LISTER, Michael; MARSH, David (orgs.). The State: theories and issues. Hampshire: Palgrave Macmillan, 2006. p. 1-20.

LIMA, Antonio Bosco de. Estado, Educação e Controle Social: introduzindo o tema. Revista Brasileira de Política e Administração da Educação, Porto Alegre, v. 25, n. 3, p. 473-488, set./dez. 2009. 
LIMA, Iana Gomes de. As ações do Estado brasileiro na educação básica: uma análise a partir do Sistema de Avaliação da Educação Básica, Porto Alegre, 2016. 266 f. Tese (Doutorado em Educação) - Programa de Pós-Graduação em Educação, Faculdade em Educação, Universidade Federal do Rio Grande do Sul, Porto Alegre, 2016.

MAFASSIOLI, Andréia da Silva. Programa Dinheiro Direto na Escola como política pública: (re)formulações e implementação (1995 - 2015), Brasil, 2014. Universidade Federal do Rio Grande do Sul - Porto Alegre, Rio Grande do Sul, Brasil. (Projeto de Tese).

MAGUIRE, Meg. Para uma Sociologia do Professor Global. In APPLE, Michael, BALL, Stephen; GANDIN, Luís Armando. Sociologia da Educação: análise internacional. Porto Alegre: Penso, 2013. P. 77-88.

NEWMAN, Janet; CLARKE, John. Gerencialismo. Educação \& Realidade, Porto Alegre, v. 37, n. 2, p. 353-381, maio/ago. 2012.

NEWMAN, Janet; CLARKE; John. Publics, Politics \& Power: remaking the public in public services. London: SAGE Publications, 2009.

NOGUEIRA, Marco Aurélio. Um Estado para a Sociedade Civil: temas éticos e políticos da gestão democrática. São Paulo: Cortez, 2011.

OFFE, Claus. Contradiciones en el Estado del Bienestar. San Lorenzo: Alianza, 1990.

OLIVEIRA, Dalila Andrade. Nova Gestão Pública e Governos DemocráticoPopulares: contradições entre a busca da eficiência e a ampliação do direito à educação. Educação e Sociedade, Campinas, v. 36, n. 132, p. 625-646, jul./set., 2015.

PERONI, Vera. Política Educacional e Papel do Estado: no Brasil dos anos 1990. São Paulo: Xamã, 2003.

YOUNG, Iris Marion. Responsibility and global justice: a social connection model. Social Philosophy and Policy, v. 23, n. 1, p. 102-130, jan./2006. 
IANA GOMES DE LIMA é professora do Programa de Pós-Graduação em Educação (Mestrado) da Universidade da Região de Joinville (UNIVILLE). E-mail: iana_glima@yahoo.com.br

LUÍS ARMANDO GANDIN é professor do Programa de Pós-Graduação em Educação e da Faculdade de Educação da Universidade Federal do Rio Grande do Sul (UFRGS) e Bolsista de Produtividade em Pesquisa do CNPq. E-mail: luis. gandin@ufrgs.br

Recebido em outubro de 2017 Aprovado em dezembro de 2017 